\title{
Severe haemolysis and renal failure in a patient with paroxysmal nocturnal haemoglobinuria
}

\author{
G H Jackson, R S Noble, Z T Maung, J Main, S R Smith, M M Reid
}

\begin{abstract}
Transfusion of about $60 \mathrm{ml}$ of $\mathrm{ABO}$ incompatible plasma in 4 units of pooled platelets precipitated severe haemolysis, unmasking the emergence of paroxysmal nocturnal haemoglobinuria (PNH), in a patient with aplastic anaemia. In vitro tests showed that her red cells were lysed by both ABO compatible and incompatible plasma from normal donors. The behaviour of this case and the in vitro results suggest that it might be hazardous to relax the longstanding recommendation on transfusing patients with PNH by restricting the washing of blood components to those containing ABO incompatible plasma.
\end{abstract}

Paroxysmal nocturnal haemoglobinuria (PNH) is a clonal hypoplastic anaemia in which the red cells are unusually sensitive to the lytic effects of activated complement as they lack decay accelerating factor and other proteins involved in protecting cells from complement mediated lysis. ${ }^{1}$ Haemolysis is a recognised complication of blood transfusion in these patients. ${ }^{2}$ Following Dacie's original recommendations, ${ }^{3}$ most texts advise the use of washed red cells when transfusion is required, but this view has recently been challenged. ${ }^{4}$ We report a case of PNH that was unmasked by the onset of severe haemolysis and renal failure following transfusion of four random donor platelet concentrates.

\section{Case report}

A 15 year old girl developed aplastic anaemia in 1978 . Her condition improved after treatment with anti-thymocyte globulin. Following non-haemolytic pyrexial transfusion reactions she received washed red cells. A sucrose lysis test was negative in 1980. A postpartum haemorrhage in 1984 required transfusion of 17 units of washed red blood cells and more than 50 units of platelet concentrates. Four units of platelet concentrates were given in 1990 to cover a laparoscopic tubal ligation. Seven months later a cervical loop biopsy was covered with four units of $\mathrm{O}$ Rhesus negative pooled and packed platelet concentrates, containing about $60 \mathrm{ml}$ of plasma. Her blood group was $A_{1}$ Rhesus positive. She became unwell, felt cold, developed loin pain and became jaundiced. The haemoglobin concentration fell by $4 \mathrm{~g} / \mathrm{dl}$. The direct Coombs' test remained negative. Renal failure was present four days after the transfusion. Both Ham's test and sucrose lysis tests were positive. PNH was diagnosed. She became anuric with plasma creatinine reaching a peak of $1911 \mu \mathrm{mol} / 1$ and potassium of $5.6 \mathrm{mmol} / \mathrm{l}$ seven days after the transfusion. Following haemodialysis for four days renal function recovered. Fresh blood samples were collected from the patient and the four platelet donors (group $\mathrm{O}$ Rhesus negative). Samples from four other group $O$ Rhesus negative and two Group A Rhesus negative subjects were tested in parallel. The four donors had passed a haemolysin screening test at the Regional Transfusion Centre. No irregular antibodies against red cells were detected in any of the serum samples. Haemolytic activity against pooled $A_{1}$ cells was present in the serum from the $O$ Rhesus negative donors and controls at a titre of $1 / 2$ or less at $37^{\circ} \mathrm{C}$. Sera from all eight group $\mathrm{O}$ Rhesus negative and both group A Rhesus negative subjects, using the same technique, lysed the patient's cells at titres of $1 / 512$ or greater.

\section{Discussion}

Evolution of PNH from aplastic anaemia is well recognised. ${ }^{5}$ The manner in which it was shown up in this case is striking. Renal failure after transfusion of about $60 \mathrm{ml}$ of plasma in pooled platelet concentrates has not previously been reported. Clearly, patients with aplastic anaemia should be screened regularly for PNH. This patient may have been protected from haemolysis in the past by washing red cells before transfusion. Alternatively, the sensitive clone may have emerged recently.

The Mayo Clinic's experience of this disease suggests that the need to transfuse washed red cells may be a myth perpetuated by the lack of opportunity to study the effects of transfusion on large numbers of affected patients. ${ }^{4}$ ABO incompatible plasma was associated with the sole case of confirmed transfusion induced haemolysis in 23 patients accumulated over 38 years. As only 18 patients in their study received solely ABO compatible blood products, their results do not exclude, with $95 \%$ confidence, a potential susceptibility to haemolysis in up to $18 \%$ of patients. In vitro tests in our case show that 
none of the donors had peculiarly strong lytic activity against normal red cells and suggest that haemolysis might have occurred even with ABO compatible platelet concentrates. The presence of activated complement in donor plasma or complement activation in the recipient by immune reactions against platelet or white cell antigens ${ }^{1}$ could explain lysis of the PNH clone.

The behaviour of this case highlights the danger of even small plasma transfusions in some patients with $\mathrm{PNH}$, and the in vitro studies raise the possibility that such life threatening complications might occur with ABO compatible plasma. It may be premature to abandon the washing of all but those blood components containing $\mathrm{ABO}$ incompatible plasma when transfusing patients with $\mathrm{PNH}$. Clearly, even platelet concentrates from $\mathrm{ABO}$ incompatible donors can prove dangerous and, despite the difficulties involved, should be washed. It will need only one documented case of haemolysis following transfusion of ABO compatible plasma to convert a "myth" into fact. We shall not challenge our patient with $\mathrm{ABO}$ compatible plasma in an attempt to provide that case.

We thank Dr P W G Saunders for the serological investigations which first showed lytic activity in the platelet donor plasma.

1 Rotoli B, Luzzatto L. Paroxysmal nocturnal haemoglobinuria. Baillière's clinical haematology. 1989;i:113-8.

2 Dacie JV. Paroxysmal nocturnal haemoglobinuria. In Weatherall DJ, Ledingham JGG, Warrell DA, eds Oxford textbook of medicine. Oxford: Oxford University Press, 1987:1954.

3 Dacie JV. Transfusion of saline-washed red cells in nocturnal haemoglobinuria (Marchiafava-Micheli disease). Clin Sci 1948;7:65-75.

4 Brecher ME, Taswell HF. Paroxysmal nocturnal hemoglobinuria and the transfusion of washed red cells. A myth revisited. Transfusion 1989;29:681-5.

5 Najean Y, Haguenauer O for the Cooperative Group for the Study of Aplastic and Refractory Anemias. Long-term (5 to 20 years) evolution of nongrafted aplastic anemias Blood 1990;76:2222-8.

\title{
Frequency of glove puncture in the post mortem
} room

\author{
J Weston, G Locker
}

\begin{abstract}
The post mortem room is a potential source of danger from contamination caused by glove punctures. The objective of this study was to assess the incidence of hand injury and hand contamination during post mortem examinations. A prospective study of injury and glove puncture rate was conducted during post mortem examinations performed in 1990 on adults in Northwick Park Hospital mortuary. Four pathologists and two assistants performed a total of 44 post mortem examinations on adults. All participants completed a questionnaire after each examination, recording the total number of gloves used and the number of hand injuries and glove perforations sustained. Just over $8 \cdot 3 \%$ of gloves were punctured; $31 \cdot 8 \%$ of these punctures went unnoticed. Evisceration was the procedure most likely to result in hand contamination.

The study highlights a significant risk which could be reduced by more care, frequent glove changes, and hand washing during post mortem examinations. In particular, gloves should be changed and hand washed when evisceration has been completed.
\end{abstract}

The protection of medical laboratory workers is of great importance and many precautionary measures have found their way into standard medical laboratory practice. One obvious safety measure is the donning of gloves before handling fresh human tissue.

The post mortem room is a potential source of danger to both pathologists and their assistants. Because pathologists are not required to protect patients from infection in the same way as surgeons are, they may neglect to protect themselves against contamination during post mortem examinations.

Like surgeons, pathologists use sharp instruments in the presence of free body fluids. Thus if they are injured they may run similar risks of contamination. Furthermore, a glove may be punctured in the course of a post mortem examination without actually incurring an injury, but a pre-existing skin lesion may become contaminated. This second risk may be compounded if the puncture goes unnoticed so that the glove is not changed and the hand not washed for some time. In particular, evisceration of the cadaver involves the use of sharp instruments and may expose jagged edges of bone that are potential sources of danger.

To quantify these risks, glove punctures and hand injuries were recorded during post mortem examinations of adults. The relative risk of the evisceration procedure was also assessed.

\section{Methods}

Four pathologists and two technicians took part in the study. One of the pathologists was of consultant grade with over 20 years of post mortem examination experience. The other three were juniors with between one and five
Correspondence to: J Weston Accepted for publication 31 July 1991 